\title{
A Pilot Feasibility Study of a Campaign Intervention for Weight Loss among Overweight and Obese Adults
}

\author{
David O. Garcia ${ }^{1}$, John M. Jakicic ${ }^{2}$, Kelliann K. Davis ${ }^{2}$, Bethany Barone Gibbs ${ }^{2}$, Lora E. Burke ${ }^{2}$, \\ and Amy D. Rickman ${ }^{2}$ \\ ${ }^{1}$ University of Arizona \\ ${ }^{2}$ University of Pittsburgh
}

\begin{abstract}
Background: Behavioral interventions produce significant short-term weight loss. However, these interventions typically require regular in-person sessions, which may not be feasible for all individuals. Purpose: The purpose of this pilot study was to evaluate the feasibility of a 12-week campaign intervention (CI) compared to a standard on-site, group-based behavioral weight loss intervention (SBWL) among overweight/obese adults. Methods: SBWL participants ( $\mathrm{n}=13$; age: $42.5 \pm 9.1$ years; BMI: $33.4 \pm 3.8 \mathrm{~kg} / \mathrm{m}^{2}$ ) attended weekly group meetings, were prescribed a daily reduced caloric goal and 200 minutes of moderate-intensity physical activity per week. CI participants $(n=13$; age: $43.8 \pm 9.0$ years; BMI: $33.2 \pm 3.8 \mathrm{~kg} / \mathrm{m}^{2}$ ) received the same recommendations as the SBWL, attended in-person group meetings at weeks 0 and 12, and received e-mail messages weeks 2-11. Additional CI features included a thematic framework and an incentive-based point system targeting behavioral goals. Results: Significant weight loss was demonstrated for intention-to-treat (SBWL: $-5.6 \pm 2.9 \mathrm{~kg}$; CI: $-3.1 \pm 3.4 \mathrm{~kg}$ ) $(\mathrm{p}<0.001)$ and completers (SBWL: $n=12 ;-6.1 \pm 2.5 \mathrm{~kg}$; CI: $n=10 ;-4.0 \pm 3.4 \mathrm{~kg})(\mathrm{p}<0.001)$, with no between group difference. Conclusion: The CI may provide an alternative approach to implement a weight loss program; however, confirmation of these findings is needed.
\end{abstract}

(c) 2014 Californian Journal of Health Promotion. All rights reserved.

Keywords: Campaign intervention, weight loss, overweight, obesity, incentives, e-mail

\section{Introduction}

The increasing prevalence of overweight and obesity in the United States is a significant public health concern, with $69 \%$ of adults classified as overweight (Body Mass Index $\left.(B M I) \geq 25.0 \mathrm{~kg} / \mathrm{m}^{2}\right)$ and $35.1 \%$ obese $(\mathrm{BMI} \geq$ $30.0 \mathrm{~kg} / \mathrm{m}^{2}$ ) (Ogden, Carroll, Kit, \& Flegal, 2014). Overweight and obesity are associated with higher rates of mortality (Cohen, Signorello, Cope, McLaughlin, Hargreaves, Zheng et al., 2012) and a multitude of negative health consequences such as: hyperinsulinemia, insulin resistance, type 2 diabetes, hypertension, dyslipidemia, coronary heart disease, and gall bladder disease (Pi-Sunyer, 2002). As a result, annual health care costs associated with obesity related health outcomes is well over $\$ 147$ billion (Finkelstein, Trogdon, Cohen, \& Dietz, 2009).
This evidence suggests that strategies to manage weight are critically important.

Weight loss treatment is recommended for individuals with a BMI of $30 \mathrm{~kg} / \mathrm{m}^{2}$ or higher, in addition to those with a BMI of $25 \mathrm{~kg} / \mathrm{m}^{2}$ or higher who have weight-related comorbidities (Jensen, Ryan, Apovian, Ard, Comuzzie, Donato et al., 2014). While there are many treatments available for overweight and obese individuals including pharmacotherapy and weight loss surgery, behavior therapy is largely considered the first line of intervention (Jensen et al., 2014). Behavior therapy refers to a set of principles and techniques to assist overweight and obese individuals in modifying eating, activity, and negative thinking habits (e.g., all or nothing) that contribute to their excess weight (Wadden, Butryn, \& Wilson, 2007). This approach recognizes that weight is affected by factors 
Garcia, D.O., Jakicic, J.M., Davis, K.K, Gibbs, B.B., Burke, L.E., Rickman, A.D. / Californian Journal of Health Promotion 2014,

Volume 12, Issue 3, 56-70.

other than behaviors, including genetic, metabolic, and hormonal influences, which may predispose some individuals to obesity (Wadden et al., 2007).

\section{Behavioral Weight Loss Interventions}

The National Heart, Lung and Blood Institute promotes using behavioral weight loss interventions as a strategy to assist individuals in restructuring their lifestyle and environment to monitor and reduce behaviors known to contribute to obesity (Berkel, Poston, Reeves, \& Foreyt, 2005). Behavioral weight loss interventions are typically provided on a weekly basis for an initial period of 16 to 26 weeks (Wadden, Crerand, \& Brock, 2005). Interventions focused on weight loss maintenance may continue after this period with biweekly sessions (Butryn, Webb, \& Wadden, 2011). Treatment is often provided in 60 to 90 minute group and/or individual sessions lead by professionals with degrees in nutrition, psychology, exercise physiology, or a related field (Butryn et al., 2011).

Sessions begin with a measurement of the participants' weight and once the group assembles participants discuss their success and/or barriers in achieving behavioral goals (Butryn et al., 2011). This is followed by the delivery and discussion of a behavioral lesson which includes topics such as self-monitoring, problem solving, nutrition, physical activity, stimulus control, goal setting, social support, cognitive restructuring, and relapse prevention (Butryn et al., 2011; Levy, Finch, Crowell, Talley, \& Jeffery, 2007; Wadden et al., 2005). Lecturing is minimal as participants are encouraged to ask questions or discuss progress in completing assignments (Wadden et al., 2005). Sessions conclude with a discussion of the homework assignment for the coming week (Wadden et al., 2005). The overarching goal of treatment is to modify a participant's lifestyle behaviors thought to contribute to obesity (e.g., inappropriate diet and inactivity), in addition to close monitoring of those behaviors (Poston \& Foreyt, 2000).

Behavioral weight loss interventions have been shown to elicit approximately an $8-10 \%$ weight loss over the course of six months (Wadden, West, Delahanty, Jakicic, Rejeski, Williamson et al., 2006) and this amount of weight loss has been shown to be associated with improved health-related outcomes such as decreased blood pressure, decreased LDL-C, increased HDL-C, decreased triglycerides, and improved glucose tolerance (Donnelly, Blair, Jakicic, Manore, Rankin, \& Smith, 2009). Despite this success, not all participants achieve or sustain this magnitude of weight loss beyond six months (Unick, Jakicic, \& Marcus, 2010), and nearly $20 \%$ of participants do not complete treatment (Wadden et al., 2007). Of the participants who do complete treatment, one-third of lost weight is regained within one year of treatment ending, and nearly one-half of participants return to their original weight within five years (Curioni \& Lourenco, 2005; Wadden et al., 2007). Furthermore, these interventions are typically intensive, requiring attendance at regular inperson sessions, which can be costly to deliver for payers (labor and non-labor costs such as staff time and supplies) and not feasible for all participants to travel and spend time in intervention sessions (Jakicic, Tate, Lang, Davis, Polzien, Rickman et al., 2012). Thus, alternative and less intensive delivery strategies are needed that will produce significant weight loss and may be more widely applied.

\section{Alternative Weight Loss Delivery Strategies}

The Internet can be a practical method to deliver behavioral weight loss interventions which may also reduce cost associated with in-person weight loss interventions. Tate and colleagues (Tate, Wing, \& Winett, 2001) examined whether an Internet behavior therapy group produced greater initial weight loss compared to an Internet education only group. All participants were given one face-to-face group session and access to a website with links to Internet weight loss resources. Participants in the behavior therapy group received 24 weekly behavioral lessons via e-mail, weekly online submission of self-monitoring diaries with individualized therapist feedback via e-mail, and an online bulletin board. The authors found participants who were given a structured behavioral treatment program online with weekly contact and individualized feedback from 
interventionists had better weight loss than those given links to education web sites (-4.1 kg vs. $1.6 \mathrm{~kg}$, respectively).

Tate et al. (Tate, Jackvony, \& Wing, 2006) also examined the short-term efficacy of a selfdirected Internet weight loss program compared with the same program supplemented with behavioral counseling from a human counselor or computer automated tailored system. All participants received one weight loss group session, coupons for meal replacements, and access to an interactive Website. In addition, the e-mail counseling group received weekly e-mail feedback from a counselor, and the computerautomated group received automated, tailored messages. At three months, weight losses for the computer-automated group (-5.3 kg) and human e-mail counseling $(-6.1 \mathrm{~kg})$ were significantly greater compared to the no counseling group ($2.8 \mathrm{~kg})$. However, there was no significant difference between the computer-automated group and the human e-mail counseling group. Thus, it appears individualized feedback from a counselor is an important component to improve weight loss outcomes within Internet-based programs.

One additional alternative strategy for weight loss is the use of behavioral campaigns. Campaigns use theoretically-based behavioral change strategies (e.g., self-monitoring, goal setting, feedback on goal attainment) to target specific behaviors and improve weight loss/weight maintenance efforts within a thematic framework (e.g., walking 10,000 steps a day to reach a beach destination) (Garcia, Rickman, \& Wisniewski, 2013). Additionally, campaigns afford participants an opportunity to earn tangible incentives (e.g., beach towel) to reinforce positive behavior change.

Various clinical trials have integrated campaigns into weight loss programs to assist individuals in changing their dietary and physical activity habits to induce and maintain weight loss. For example, both the Diabetes Prevention Program (DPP) and the Look AHEAD (Action for Health in Diabetes) trials have incorporated campaigns into the lifestyle intervention to assist participants in the attainment of lifestyle study goals (Diabetes Prevention Program (DPP) Research Group, 2002; Wadden et al., 2006). Nationwide centers, local teams, and individuals have competed on best attendance, regular selfmonitoring, weight loss, minutes of physical activity, or steps measured by a pedometer in a variety of 6 to 10 week campaigns (DPP Research Group, 2002; Wadden et al., 2006). Overall the lifestyle intervention in the DPP showed weight loss to be effective at reducing diabetes incidence by $58 \%$ for those at high risk for the disease when compared to a control group (Hamman, Wing, Edelstein, Lachin, Bray, Delahanty et al., 2006). More recently, the lifestyle intervention of Look AHEAD has shown that weight loss is associated with improved fitness, glycemic control, and cardiovascular risk factors in individuals with type 2 diabetes, but it did not reduce the rate of cardiovascular events in overweight and obese adults with type 2 diabetes (Look AHEAD Research Group, 2013).

Data from the DPP National Lifestyle Lottery demonstrated increases in the average percent of weight loss, average minutes of physical activity, percent of participants at weight goal, and percent of participants at their physical activity goal during the time the campaign was implemented as part of the larger intervention (Wing \& Gillis, 1996). While it appears campaigns within behavioral interventions may be a useful intervention delivery tool to support weight loss efforts, data from other DPP and Look AHEAD campaigns have not been published or made available to the public. Further, it is not currently known the degree to which a campaign-themed intervention, with minimal face-to-face contact, impacts weight loss. Therefore, the purpose of this pilot study was to evaluate the feasibility of a 12-week email based campaign intervention (CI) compared to a standard on-site, group-based behavioral weight loss intervention (SBWL).

\section{Methods}

\section{Participants}

Eligible participants were male or non-pregnant female, overweight/obese (BMI 25-45 kg/m²) adults between 18-55 years of age. Adults who 
regularly participated in exercise (at least 20 minutes/day on at least 3 days/week), were currently taking any medication that may affect metabolism or body weight (e.g., synthroid), had a weight loss of $\geq 5 \%$ in the previous 6 months, or participated in a previous physical activity or weight management research project in the previous 6 months were excluded. Because of the need to access campaign material in the CI group, individuals who did not have access to a computer or e-mail were also excluded. All participants provided written informed consent and obtained a physician's medical clearance/approval for participation. The trial was approved by the IRB at the University of Pittsburgh.

\section{Study Design}

Participants were randomly assigned to one of two groups using a stratified (gender, ethnicity) randomized block design: 1) SBWL ( $\mathrm{n}=13)$ or 2$)$ CI $(n=13)$. The SBWL and CI were delivered by two of the investigators, a registered dietitian and a certified American College of Sports Medicine Clinical Exercise Specialist ${ }^{\circledR}$, with prior experience teaching behavioral lessons.

\section{Intervention}

$S B W L$. The theoretical foundation of the 12week SBWL was based on Social Cognitive Theory (Bandura, 2001) and Problem Solving Theory (D'Zurilla \& Goldfried, 1971) and involved participants changing eating behaviors, increasing physical activity and attending weekly group meetings at the University of Pittsburgh Physical Activity and Weight Management Research Center. Behavioral lessons including topics such as problem solving and goal setting were discussed in group meetings to help participants adopt and maintain eating and physical activity behaviors.

Participants were prescribed a calorie and fat gram goal to reduce total energy intake to approximately 1200-1800 calories per day dependent on their initial body weight ( $<200$ lbs. $=1200 \mathrm{kcal} /$ day; $200-250$ lbs. $=1500 \mathrm{kcal} /$ day; $>250$ lbs. = $1800 \mathrm{kcal} /$ day) (Jensen et al., 2014). The goal for total fat intake was $20-30 \%$ of total caloric intake, which is consistent with the 2010 Dietary Guidelines for Americans (U.S.
Department of Health and Human Services, 2010). Participants were also prescribed weekly exercise goals with the duration increasing from 15 to 40 minutes, 5 days a week, over the 12week program. Brisk walking, or other similar activities, was recommended as the primary mode of exercise. Lastly, participants selfmonitored food and planned exercise in a daily diary. This information was reviewed by the interventionists weekly and used to provide feedback in the form of brief comments written on the diary. For example: "You did an excellent job achieving your physical activity goal this week. It appears you had some difficulty staying within your calorie goal. What do you think you can do differently to be successful? The lesson from two weeks ago on planning meals in advance may help. Keep up the great efforts and have a wonderful week!”

CI. The CI participants received the same dietary and physical activity recommendations as the SBWL across the 12-weeks; however, they attended in-person group meetings only at weeks 0 and 12, and received e-mail messages in weeks 2-11. Additional CI features included a thematic race car framework and an incentivebased point system targeting study behavioral goals. The CI features are described in further detail in Table 1.

\section{Intervention Fidelity Plan}

To monitor and enhance the reliability and validity of the CI, we developed a treatment fidelity plan described in Table 2. This plan was based on best practices and recommendations from the National Institutes of Health Behavior Change Consortium (BCC) for enhancing treatment fidelity in health behavior change studies (Bellg, Borrelli, Resnick, Hecht, Minicucci, Ory et al., 2004). It addressed the design of the study, monitoring the delivery of the intervention, receipt of the treatment by the participant, and enactment to ensure that the participant performed the skills and strategies as intended by the intervention.

\section{Intervention Components Summary}

In summary, Table 3 illustrates the dietary and physical activity components common to the 
Garcia, D.O., Jakicic, J.M., Davis, K.K, Gibbs, B.B., Burke, L.E., Rickman, A.D. / Californian Journal of Health Promotion 2014, Volume 12, Issue 3, 56-70.

two randomized groups, plus the alternative treatment components received by the CI group.

\section{Table 1}

Intervention Features of the Campaign Intervention (CI)

Thematic
Framework

Incentive-
Based Point
System

Incentive Drawing System

SelfMonitoring Procedures

\section{In-Person Group Sessions (Weeks 1 \& 12)}

\section{Group and Individual E-mails (Weeks 2-11)}

- Weight Loss, Diet, and Activity (W.L.D.A.) Cup

o Designed to have participants "race” towards achieving dietary, physical activity and weight loss goals

o Thematic framework was incorporated into behavioral lessons content, targeted campaign goals, and feedback on progress

- W.L.D.A. Cup points were accumulated from week 2 to week 11 (10-weeks of data collection)

0 Participants earned points by self-reporting diet and physical behaviors, and body weight

- Food intake 5 out of 7 days = 1 point; body weight at least once during the week $=1$ point; achieving the weekly physical activity goal $=1$ point

o Interventionists tracked points for participants and informed them of their weekly totals

o Weight loss points were awarded at the final in-person group session at week 12

- Points were based on total percent weight loss from the initial in-person group session

- $1-1.9 \%=5$ points; $2-3.9 \%=10$ points; $4-4.9 \%=15$ points; $\geq 5 \%=20$ points

- $\quad$ Tickets were awarded at the end of week 12 based on individual point totals

o 5-9 points $=3$ tickets; $10-19$ points $=5$ tickets; $20-29$ points $=10$ tickets; $30-39$ points $=15$ tickets; and 40-50 points $=25$ tickets

- Participants had the opportunity to win incentives which were announced at the initial group session

o Water bottle, pedometer, stability ball, Apple iPod Shuffle, or Apple iPod Nano (participants were eligible to win only one incentive)

o All participants who achieved the overall weight loss goal (5\% of initial body weight) were awarded a gym bag and certificate for successful weight loss efforts

- Self-monitoring information (e.g., food intake, physical activity minutes, and body weight) reported each week via an e-mail.

o Comments/questions were submitted if a participant wanted to provide a justification for their progress or clarify how to use strategies within behavioral lesson materials to achieve study goals

o E-mail procedures were reviewed at the first group session and any questions were addressed

o W.L.D.A. Cup points were awarded if the e-mail was received by specific date and time each week

o In the event the deadline was not met, participants were still able to report their information to assist interventionists with counseling; however they were not awarded W.L.D.A. Cup points for that week

- The initial in-person group session reviewed the core components of the overall intervention and then the additional features of the CI

o Participants were also given an overview document which included weekly goals, an intervention calendar, and a clear explanation of how they can earn chances to win incentives

- The in-person group session at week 12 was a summary session on how the participants did in the CI

0 The individual and group W.L.D.A. cup point standings were also revealed followed by the incentive drawing

- One thematic group e-mail message including the behavioral lesson, goal assignments, and feedback on group progress was sent per week

- Each participant also received one e-mail message per week including individualized feedback

o This feedback included brief comments on progress towards W.L.D.A. Cup points, reinforced study goals, and encouraged participants to stay engaged in the campaign "race." In addition, any comments/questions participants submitted the previous week were addressed.

- $\quad$ E-mails were sent from a secured study e-mail address

o Participants were instructed not to respond to an e-mail message; however, any replies from participants were printed and filed accordingly 


\section{Table 2}

Intervention Fidelity Plan

\section{Study Component}

\author{
Design
}

Monitoring

Intervention Delivery

Intervention Receipt

Enactment

\section{Fidelity Plan}

- Behavioral lesson content identical between intervention groups

- Individual and group feedback on progress provided at fixed intervals (once per week)

- Fixed duration of in-person group sessions (60 minutes)

- Any deviations from protocol with regard to number, length, and frequency of contacts were recorded

- Guidelines for e-mail content established

- Recorded frequency and duration spent drafting e-mail responses

- Emails messages copied to and monitored by investigators

- Email messages sent and received were printed and filed weekly

- During the two in-person group sessions, the SBWL group sessions occurred in separate area within the center to minimize potential problems of confounding by contamination

Monitoring of CI participants:

- Diet and physical activity behaviors, and body weight were recorded Monitoring of counseling via e-mail:

- Return receipt was used to monitor opening of email messages

- Replies from participants were printed and filed (if needed)

- Collected self-monitoring data for diet and physical activity behaviors, and body weight to observe attainment of goals

- Assessed outcome measures: weight, dietary intake, physical activity, and self-efficacy and motivation for weight loss at week 0 and 12

\section{Outcome Measures and Procedures}

Outcome measurements were conducted by one of the investigators (D.O.G.). Height was measured to the nearest 0.01 centimeter $(\mathrm{cm})$ at week 0 and 12 using a wall-mounted stadiometer (Perspective Enterprises; Portage, MI) with participants removing their shoes prior to the measurement. Body weight was measured to the nearest $0.1 \mathrm{~kg}$ on a Tanita WB-110A digital scale (Tanita Corporation; Arlington Heights, IL) with subjects in a lightweight hospital gown. Dietary intake (kcals/day) was estimated using the Block Food Frequency Questionnaire (FFQ) (Block, 2005, Dietary Data Systems, Berkeley, CA) (Block, Woods, Potosky, \& Clifford, 1990). Physical activity was assessed by an interviewer-administered Paffenbarger Physical Activity Questionnaire (Paffenbarger, Hyde, Wing, \& Hsieh, 1986), and converted into physical activity minutes (Ainsworth, Haskell, Herrmann, Meckes, Bassett, Tudor-Locke et al., 2011; Paffenbarger, Wing, \& Hyde, 1978).
Participants received $\$ 50$ for completing the assessments at week 0 and 12 .

\section{Statistical Analyses}

Statistical analyses were performed using the Statistical Package for the Social Sciences (IBM-SPSS, version 21.0). Baseline characteristics were compared using the chisquare $\left(\chi^{2}\right)$ test for categorical variables and independent samples t-tests for continuous variables. Analyses were performed using the Shapiro-Wilk test to examine normality. For physical activity data that were not normally distributed, nonparametric tests (Mann Whitney $\mathrm{U}$ Test) were performed to examine changes between groups and across time. Two-factor repeated measures (group $\mathrm{X}$ time) ANOVAs examined differences between groups for weight loss, physical activity, and dietary intake at 0 and 12 weeks. Intention-to-treat was used in the analyses; missing data was accounted for by carrying the baseline data forward for participants who did not complete the 12-week visit. Statistical significance was set at the 
Garcia, D.O., Jakicic, J.M., Davis, K.K, Gibbs, B.B., Burke, L.E., Rickman, A.D. / Californian Journal of Health Promotion 2014, Volume 12, Issue 3, 56-70.

$\mathrm{p}<0.05$ level of confidence. Given the small intervals also are provided. sample size of the study, 95\% confidence

Table 3

Treatment Components of the SBWL and CI Groups

\begin{tabular}{|c|c|c|}
\hline & $\begin{array}{l}\text { Standard Behavioral } \\
\text { Weight Loss Program }\end{array}$ & Campaign Intervention \\
\hline \multicolumn{3}{|l|}{ Frequency and Type of Contact } \\
\hline $\begin{array}{l}\text { Weekly In-Person Group Sessions } \\
\text { (Weeks 1-12) }\end{array}$ & $\mathrm{X}$ & \\
\hline $\begin{array}{l}\text { In-Person Group Sessions } \\
\text { (Weeks } 1 \text { \& 12) }\end{array}$ & & $\mathrm{X}$ \\
\hline $\begin{array}{l}\text { Group and Individual E-mails } \\
\text { (Weeks 2-11) }\end{array}$ & & $\mathrm{X}$ \\
\hline \multicolumn{3}{|l|}{ Dietary Component } \\
\hline $\begin{array}{l}\text { Reduced Calorie Diet } \\
(1200-1800 \text { kcals/day) }\end{array}$ & $\mathrm{X}$ & $\mathrm{X}$ \\
\hline $\begin{array}{l}\text { Fat Intake at } 20-30 \% \\
\text { of Total Intake }\end{array}$ & $\mathrm{X}$ & $\mathrm{X}$ \\
\hline Meal Plans, Calendars, and Recipes & $\mathrm{X}$ & $\mathrm{X}$ \\
\hline Recorded Food Intake in a Paper Diary & $\mathrm{X}$ & \\
\hline Reported Food Intake via E-mail & & $\mathrm{X}$ \\
\hline \multicolumn{3}{|l|}{ Physical Activity Component } \\
\hline Progressed to $200 \mathrm{~min} /$ week & $\mathrm{X}$ & $\mathrm{X}$ \\
\hline Supervised Physical Activity Weekly & $\mathrm{X}$ & \\
\hline $\begin{array}{l}\text { Recorded Physical Activity } \\
\text { in a Paper Diary }\end{array}$ & $\mathrm{X}$ & \\
\hline Reported Physical Activity via E-mail & & $\mathrm{X}$ \\
\hline \multicolumn{3}{|l|}{ Additional Components } \\
\hline $\begin{array}{l}\text { Thematic Framework } \\
\text { (W.L.D.A. Cup Race Car Theme) }\end{array}$ & & $\mathrm{X}$ \\
\hline Incentive-Based Point System & & $\mathrm{X}$ \\
\hline Lottery Drawing and Incentives & & $\mathrm{X}$ \\
\hline
\end{tabular}

\section{Results}

Twenty-six overweight and obese adults were enrolled in the study and randomized to one of the two treatment conditions (Figure 1). Demographic characteristics are shown in Table 4. There were no significant differences between randomized groups at baseline for age, weight, and BMI. Chi-Square analyses revealed no significant between-group differences on gender $(p=1.000)$ and race $(p=1.000)$ at baseline. The overall attrition rate of this investigation was $15.4 \%$, with 22 of 26 participants completing assessments at week 12. Attrition did not differ by treatment assignment (SBWL: $\mathrm{n}=1,7.7 \%$ vs. CI: $n=3,23.1 \%)$ based on $\chi^{2}$ analysis $(p=0.28)$. Participants were lost at follow-up due to lack of time $(\mathrm{n}=1)$, a medical reason $(\mathrm{n}=1)$, and unknown reasons $(\mathrm{n}=2)$.
Analyses revealed a significant weight loss for both groups (SBWL: $-5.6 \pm 2.9 \mathrm{~kg}$; CI: $-3.1 \pm$ $3.4 \mathrm{~kg})(\mathrm{p}<0.001)$. In addition, both groups significantly reduced daily energy intake (SBWL: $-474.9 \pm 509.0 \mathrm{kcal} /$ day; CI: $-242.5 \pm$ $709.3 \mathrm{kcal} /$ day) $(\mathrm{p}<0.01)$, and increased physical activity (SBWL: $141.7 \pm 88.3$ minutes/week; CI: $146.8 \pm 224.9$ minutes/week $)(p<0.001)$ from week 0 to week 12, with no between group differences (Table 5). Changes in body weight, energy intake, and physical activity were also examined for the completers in the SBWL $(n=12)$ and CI $(n=10)$, and revealed no differences from the results found when we included the non-completers. Further, there were no significant differences in self-reported calorie intake ( $\mathrm{kcal} /$ day $) \quad(\mathrm{p}=0.22)$, self-reported physical activity $(\mathrm{p}=0.17)$, and self-weighing 
Garcia, D.O., Jakicic, J.M., Davis, K.K, Gibbs, B.B., Burke, L.E., Rickman, A.D. / Californian Journal of Health Promotion 2014, Volume 12, Issue 3, 56-70.

(days/wk) $(\mathrm{p}=0.92)$ between groups. Overall CI participants earned 187 out of 390 (48\%) W.L.D.A. points and $30.8 \%(\mathrm{n}=4)$ achieved the $5 \%$ weight loss goal, earning a gym bag and certificate for successful weight loss efforts. Weight loss was not associated with total individual points earned $\quad(p=0.08)$.

Table 4

\begin{tabular}{lcccc}
\hline \multicolumn{1}{c}{ Characteristics } & $\begin{array}{c}\text { Total } \\
\mathbf{( N = 2 6 )}\end{array}$ & $\begin{array}{c}\text { SBWL } \\
(\mathbf{n}=\mathbf{1 3})\end{array}$ & $\begin{array}{c}\text { CI } \\
(\mathbf{n = 1 3})\end{array}$ & $\mathbf{p}$ \\
\hline Mean Age (years) (SD) & $43.1 \pm 8.9$ & $42.5 \pm 9.1$ & $43.8 \pm 9.0$ & 0.715 \\
Mean Weight (kg) (SD) & $92.2 \pm 13.1$ & $91.5 \pm 13.0$ & $92.9 \pm 13.7$ & 0.787 \\
Mean Body Mass Index $\left(\mathrm{kg} / \mathrm{m}^{2}\right)(\mathrm{SD})$ & $33.3 \pm 3.7$ & $33.4 \pm 3.8$ & $33.2 \pm 3.8$ & 0.874 \\
Gender & & & & \\
$\quad$ \% Males & $15.4 \%(\mathrm{~N}=4)$ & $15.4 \%(\mathrm{~N}=2)$ & $15.4 \%(\mathrm{~N}=2)$ & 1.000 \\
$\quad$ \% Females & $84.6 \%(\mathrm{~N}=22)$ & $84.6 \%(\mathrm{~N}=11)$ & $84.6 \%(\mathrm{~N}=11)$ & \\
Race & & & & \\
$\quad$ \% African-American & $15.4 \%(\mathrm{~N}=4)$ & $15.4 \%(\mathrm{~N}=2)$ & $15.4 \%(\mathrm{~N}=2)$ & 1.000 \\
\hline
\end{tabular}

$\mathrm{SD}=$ standard deviation

The p values were obtained using chi-square tests for categorical variables and independent samples t- tests for continuous variables.

Table 5

Outcomes Differences Between Treatment Groups at Week 12: Intention-to-Treat Analyses

\begin{tabular}{|c|c|c|c|c|c|c|}
\hline \multirow[b]{2}{*}{ Outcome Variable } & \multicolumn{2}{|c|}{ Baseline } & \multicolumn{2}{|c|}{ 12-Week Follow Up } & \multirow[b]{2}{*}{$\begin{array}{c}\text { Difference } \\
\text { Between Groups } \\
(95 \% \text { CI }) \\
\end{array}$} & \multirow[b]{2}{*}{$\mathbf{p}$} \\
\hline & SBWL & $\begin{array}{c}\text { Campaign } \\
\text { Intervention }\end{array}$ & SBWL & $\begin{array}{c}\text { Campaign } \\
\text { Intervention }\end{array}$ & & \\
\hline Mean Weight (kg) (SD) & $91.5 \pm 13.0$ & $92.9 \pm 13.7$ & $85.8 \pm 12.5$ & $89.8 \pm 13.5$ & -5.1 to 0.03 & 0.052 \\
\hline $\begin{array}{l}\text { Mean Body Mass Index } \\
\left(\mathrm{kg} / \mathrm{m}^{2}\right)(\mathrm{SD})\end{array}$ & $33.4 \pm 3.8$ & $33.2 \pm 3.8$ & $31.4 \pm 3.2$ & $32.1 \pm 3.9$ & -1.94 to 0.07 & 0.067 \\
\hline $\begin{array}{c}\text { Mean Dietary Intake } \\
\text { (kcal/day) (SD) }\end{array}$ & $1868.5 \pm 767.5$ & $\begin{array}{c}1913.9 \pm 69 \\
6.7\end{array}$ & $\begin{array}{c}1393.6 \pm 60 \\
7.2\end{array}$ & $1671.4 \pm 657.5$ & -732.1 to 267.36 & 0.347 \\
\hline $\begin{array}{c}\text { Mean Physical Activity } \\
\text { (mins/week) (SD) } \dagger\end{array}$ & $98.4 \pm 109.4$ & $86.3 \pm 82.9$ & $240.1 \pm 94.2$ & $233.1 \pm 217.1$ & -143.40 to 133.24 & $0.960 \dagger$ \\
\hline
\end{tabular}

$\mathrm{SD}=$ standard deviation

†Mann-Whitney U Test performed for nonparametric data

\section{Discussion}

Overall, the findings of this investigation demonstrated that both groups can produce significant weight loss, and there were no significant differences between groups. While the weight loss in the CI group did not approach the same magnitude of weight loss as a face-toface intervention; it may provide a low-intensity and potentially cost-effective approach to expand the reach and audience of weight loss treatment programs. This could have a substantial impact on health outcomes for overweight and obese individuals at risk for developing chronic diseases who cannot participate in face-to-face treatment due to the many constraints of this type of program. 


\section{Figure 1}

Study Recruitment and Retention Between Groups

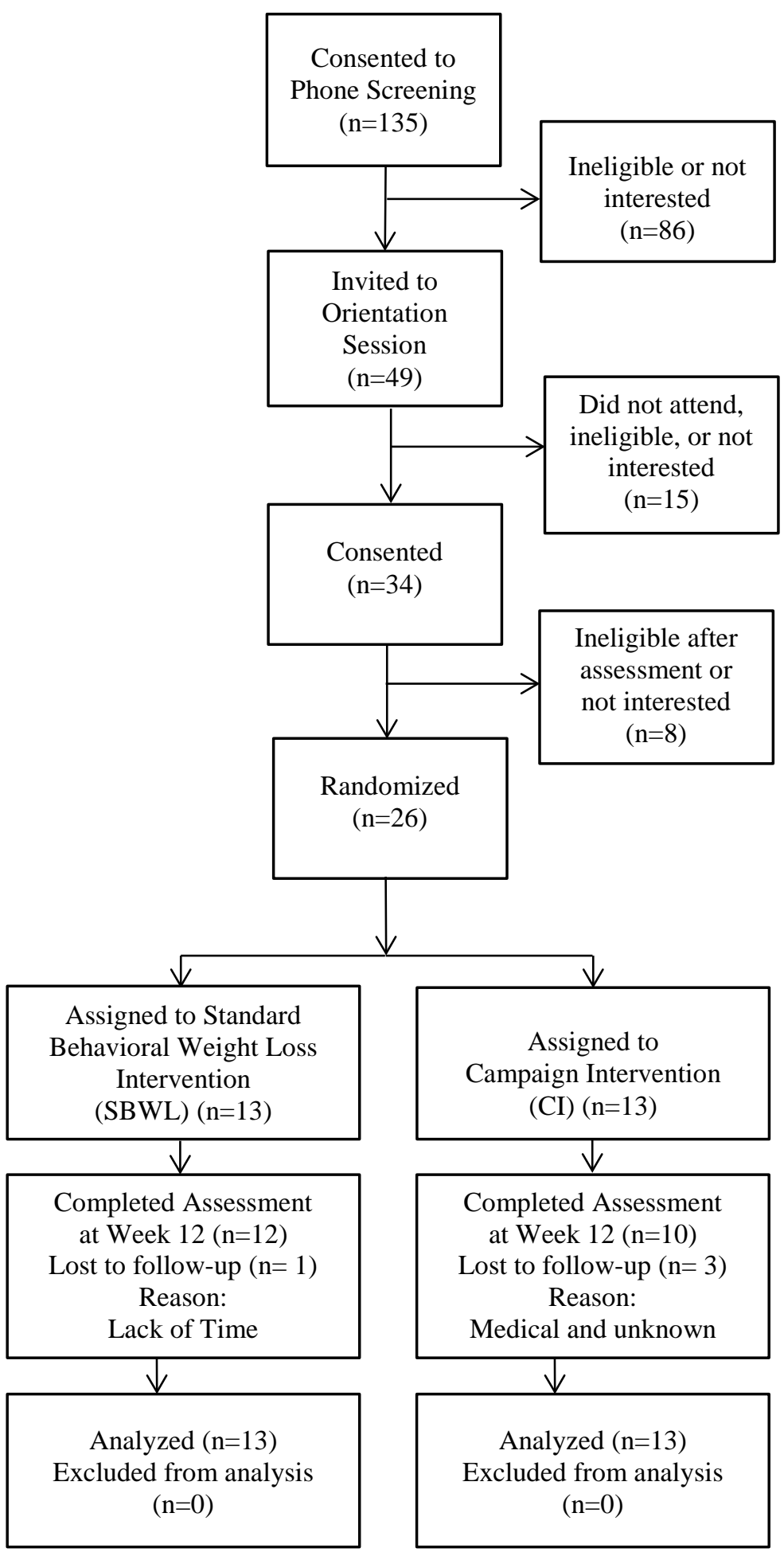


Garcia, D.O., Jakicic, J.M., Davis, K.K, Gibbs, B.B., Burke, L.E., Rickman, A.D. / Californian Journal of Health Promotion 2014,

Volume 12, Issue 3, 56-70.

Attendance at weekly group sessions was $91.6 \pm 17.7 \%$ among SBWL participants with $91.6 \pm 18.0 \%$ of self-monitoring food and activity diaries completed across the 12 weeks. CI participants did not attend weekly group meetings. Instead, CI participants submitted summary information (calories/day, fat grams/day, physical activity minutes/day, and daily body weight) from the food and activity diary via email each week. CI participants submitted this information $60.1 \pm 38.5 \%$ of possible weeks over the course of the intervention. While direct comparisons cannot be made between the number of diaries that were submitted in person by the SBWL group or submitted via e-mail by the CI group, overall it appears that participants in the SBWL group self-monitored more consistently. This may be the possible explanation for the greater magnitude of weight loss in the SBWL.

Our CI approach included both an incentive-based point system and individual weekly personalized emails sent to participants that commented on their progress and provided them feedback. This approach was associated with an average weight loss of $-3.1 \pm 3.4 \mathrm{~kg}$. By comparison, in another study, participants in an online structured behavioral treatment program that included weekly email contact and individualized feedback from an interventionist achieved weight loss of $-3.2 \pm 2.9 \mathrm{~kg}$ across 12-weeks (Tate et al., 2001). Additionally, a minimal contact e-mail intervention resulted in an average weight loss of $3.4 \mathrm{~kg}$ over 12 weeks (Gabriele, Carpenter, Tate, \& Fisher, 2011). Thus, because of the similar magnitudes of weight loss, it is possible that the email component of our intervention rather than the incentive campaign was responsible for the weight loss observed; however, our design does not allow us to disentangle these intervention components.

Petry and colleagues (Petry, Barry, Pescatello, \& White, 2011) have shown that participants receiving weekly reinforcement prizes (valued from $\$ 1$ to $\$ 100$ ) in a 12-week weight loss program lost significantly more weight $(-6.1 \mathrm{~kg})$ compared to a non-reinforcement standard weight loss program condition $(-2.7 \mathrm{~kg})$. Similarly, participants in a lottery incentive group and deposit contract group who earned chances to win money for achieving a weekly weigh-in goal $(1 \mathrm{lb}$. per week) lost more weight $(-5.9 \mathrm{~kg}$ and $-6.3 \mathrm{~kg}$, respectively) than those in a control condition $(-1.8 \mathrm{~kg})$ over the course of a 16-week study (Volpp, John, Troxel, Norton, Fassbender, \& Loewenstein, 2008). The studies by Petry et al. (2011) and Volpp et al. (2008) gave participants the opportunity to earn incentives weekly, whereas participants in the CI group in this current study earned points towards chances to win incentives at only one time point (week 12). This differential observation suggests incentives may improve weight loss outcomes short-term if they occur immediately. Future research should examine if incentives help sustain weight loss long-term.

Participants in the CI group self-reported $233.1 \pm 17.1$ minutes/week of physical activity at week 12. These results are consistent with the level of physical activity recommended by the American College of Sports Medicine, suggesting that 150-250 minutes of moderate intensity physical activity per week is needed to induce modest weight loss and prevent weight gain with moderate diet restriction (Donnelly et al., 2009). The overall increases in self-reported physical activity observed in this study are similar to previous in-person behavioral weight loss interventions (Jakicic et al., 2012) and e-mailed based programs (Tate et al., 2001, 2006) at 12 weeks. Therefore, a CI complete with regular email communication may be used as a strategy to increase physical activity to assist with weight management.

Previous research has shown that reduced dietary intake, in combination with adopting healthy eating behaviors, are important components to assist individuals in losing weight (Unick, et al., 2010). The CI group significantly reduced daily energy intake (-242.5 $\pm 709.3 \mathrm{kcal} /$ day). Reductions in dietary intake in the CI group were slightly lower than previous e-mail based programs. For example, Tate and colleagues $(2001,2006)$ reduced dietary intake by approximately 500 kcals/days in a 12-week e-mail based program. Furthermore, the dietary intake change for the CI group was approximately 200 kcals per day lower compared to the SBWL group (-474.9 $\pm 509.0 \mathrm{kcal} / \mathrm{day})$. One possible explanation for this difference is that the CI did not reinforce the achievement of specific calorie goals. Therefore, it may be possible that 
greater reductions in dietary intake would have been observed in the CI group if this was addressed within the context of the thematic framework.

\section{Limitations}

There are limitations to this investigation that should be acknowledged. The sample was small, and while significant 12-week weight loss was demonstrated, the study may have been underpowered to detect significant differences in outcome measures between the treatment groups. Results from this study can serve as pilot data to estimate sample size for a larger clinical trial to determine the effectiveness of the CI approach, and this trial should also be adequately powered to examine the efficacy of this intervention strategy by various demographic characteristics (gender, race/ethnicity, etc.). Using the variability in weight loss from our data, with $80 \%$ power, and assuming that a difference in weight loss of $<2.5 \mathrm{~kg}$ between groups would not be clinically meaningful; a future trial comparing the less intense CI to the SBWL (gold standard) would need 46 subjects (23 per group). Additionally, it is unclear if the effects of the CI would persist long-term. Therefore, the application of CI to assist with weight maintenance efforts beyond six months and the prevention of weight regain warrants further investigation in a longer trial.

Lastly, CI participants earned chances to win incentives provided at the end of the study, based upon frequency of submission of self-monitoring information (e.g., food intake, physical activity minutes, and body weight) throughout the study. It is unclear if chances to win incentives and the campaign theme influenced the CI participants' motivation for reporting their self-monitoring information as this was not measured. Future studies should examine the role of the campaign theme and incentive magnitude (perceived value of the incentive) and frequency on desired behavior change within the context of CI participation.

\section{Conclusion}

Short-term weight loss was achieved using a CI including a thematic intervention framework and an incentive-based point system. Therefore, the CI may provide an alternative approach to assist individuals with weight loss efforts, particularly in settings where on-site weight loss delivery efforts may be a challenge (such as clinics or worksite wellness programs in which access to facilities is reduced due to high demand). Future studies should conduct focus groups and interviews prior to the implementation of the CI to address limitations of this investigation. In addition, future studies should evaluate the efficacy of the CI long-term to determine whether these findings can be sustained beyond 12-weeks and what components of the CI are most effective.

\section{Acknowledgements}

The project described was supported by the University of Pittsburgh School of Education and Department of Health and Physical Activity and the National Institutes of Health through Grant Numbers UL1 RR024153 and UL1TR000005. 
Garcia, D.O., Jakicic, J.M., Davis, K.K, Gibbs, B.B., Burke, L.E., Rickman, A.D. / Californian Journal of Health Promotion 2014, Volume 12, Issue 3, 56-70.

\section{References}

Ainsworth, B. E., Haskell, W. L., Herrmann, S. D., Meckes, N., Bassett, D. R., Jr., Tudor-Locke, C., et al. (2011). 2011 Compendium of physical activities: A second update of codes and MET values. Medicine \& Science in Sports \& Exercise, 43(8), 1575-1581.

Bandura, A. (2001). Social cognitive theory: An agentic perspective. Annual Review of Psychology, 52, 126.

Bellg, A. J., Borrelli, B., Resnick, B., Hecht, J., Minicucci, D. S., Ory, M., et al. (2004). Enhancing treatment fidelity in health behavior change studies: Best practices and recommendations from the NIH behavior change consortium. Health Psychology, 23(5), 443-451.

Berkel, L. A., Poston, W. S., Reeves, R. S., \& Foreyt, J. P. (2005). Behavioral interventions for obesity. Journal of the American Dietetic Association, 105(5 Suppl 1), S35-43.

Block, G., Woods, M., Potosky, A., \& Clifford, C. (1990). Validation of a self-administered diet history questionnaire using multiple diet records. Journal of Clinical Epidemiology, 43(12), 1327-1335.

Butryn, M. L., Webb, V., \& Wadden, T. A. (2011). Behavioral treatment of obesity. Psychiatric Clinics of North America, 34(4), 841-859.

Cohen, S. S., Signorello, L. B., Cope, E. L., McLaughlin, J. K., Hargreaves, M. K., Zheng, W., et al. (2012). Obesity and all-cause mortality among black adults and white adults. American Journal of Epidemiology, 176(5), 431-42.

Curioni, C. C., \& Lourenco, P. M. (2005). Long-term weight loss after diet and exercise: A systematic review. International Journal of Obesity, 29(10), 1168-1174.

D'Zurilla, T. J., \& Goldfried, M. R. (1971). Problem solving and behavior modification. Journal of Abnormal Psychology, 78(1), 107-126.

Donnelly, J. E., Blair, S. N., Jakicic, J. M., Manore, M. M., Rankin, J. W., \& Smith, B. K. (2009). American College of Sports Medicine Position Stand. Appropriate physical activity intervention strategies for weight loss and prevention of weight regain for adults. Medicine \& Science in Sports \& Exercise, 41(2), 459-471.

Finkelstein, E. A., Trogdon, J. G., Cohen, J. W., \& Dietz, W. (2009). Annual medical spending attributable to obesity: Payer-and service-specific estimates. Health Affairs, 28(5), w822-831.

Gabriele, J. M., Carpenter, B. D., Tate, D. F., \& Fisher, E. B. (2011). Directive and nondirective e-coach support for weight loss in overweight adults. Annals of Behavioral Medicine : A publication of the Society of Behavioral Medicine, 41(2), 252-263.

Garcia, D.O., Rickman, A., \& Wisniewski L. (2013). Winning losers at work: Organizing worksite competitions to promote weight management. ACSM Health and Fitness Journal, 17(1), 15-21.

Jakicic, J. M., Tate, D. F., Lang, W., Davis, K. K., Polzien, K., Rickman, A. D., et al. (2012). Effect of a stepped-care intervention approach on weight loss in adults: A randomized clinical trial. Journal of the American Medical Association, 307(24), 2617-2626.

Jensen, M. D., Ryan, D. H., Apovian, C. M., Ard, J. D., Comuzzie, A. G., Donato, K. A., et al. (2014). 2013 AHA/ACC/TOS guideline for the management of overweight and obesity in adults: A report of the American College of Cardiology/American Heart Association Task Force on Practice Guidelines and The Obesity Society. Journal of the American College of Cardiology, 63(25 Pt B), 2985-3023.

Levy, R. L., Finch, E. A., Crowell, M. D., Talley, N. J., \& Jeffery, R. W. (2007). Behavioral intervention for the treatment of obesity: Strategies and effectiveness data. American Journal of Gastroenterology, 102(10), 2314-2321.

Ogden, C. L., Carroll, M. D., Kit, B. K., \& Flegal, K. M. (2014). Prevalence of childhood and adult obesity in the United States, 2011-2012. Journal of the American Medical Association, 311(8), 806-814.

Paffenbarger, R. S., Jr., Hyde, R. T., Wing, A. L., \& Hsieh, C. C. (1986). Physical activity, all-cause mortality, and longevity of college alumni. The New England Journal of Medicine, 314(10), 605613. 
Garcia, D.O., Jakicic, J.M., Davis, K.K, Gibbs, B.B., Burke, L.E., Rickman, A.D. / Californian Journal of Health Promotion 2014, Volume 12, Issue 3, 56-70.

Paffenbarger, R. S., Jr., Wing, A. L., \& Hyde, R. T. (1978). Physical activity as an index of heart attack risk in college alumni. American Journal of Epidemiology, 108(3), 161-175.

Petry, N. M., Barry, D., Pescatello, L., \& White, W. B. (2011). A low-cost reinforcement procedure improves short-term weight loss outcomes. The American Journal of Medicine, 124(11), 10821085.

Pi-Sunyer, F. X. (2002). The obesity epidemic: Pathophysiology and consequences of obesity. Obesity Research, 10 Suppl 2, 97S-104S.

Poston, W. S., 2nd, \& Foreyt, J. P. (2000). Successful management of the obese patient. American Family Physician, 61(12), 3615-3622.

Tate, D. F., Jackvony, E. H., \& Wing, R. R. (2006). A randomized trial comparing human e-mail counseling, computer-automated tailored counseling, and no counseling in an Internet weight loss program. Archives of Internal Medicine, 166(15), 1620-1625.

Tate, D. F., Wing, R. R., \& Winett, R. A. (2001). Using Internet technology to deliver a behavioral weight loss program. Journal of the American Medical Association, 285(9), 1172-1177.

The Diabetes Prevention Program (DPP): Description of lifestyle intervention. (2002). Diabetes Care, 25(12), 2165-2171.

The Look AHEAD Research Group., Wing, R. R., Bolin, P., Brancati, F. L., Bray, G. A., Clark, J. M., et al. (2013). Cardiovascular effects of intensive lifestyle intervention in type 2 diabetes. The New England Journal of Medicine, 369(2), 145-154.

Unick, J. L., Jakicic, J. M., \& Marcus, B. H. (2010). Contribution of behavior intervention components to 24-month weight loss. Medicine \& Science in Sports \& Exercise, 42(4), 745-753.

United States Department of Health and Human Services. Dietary Guidelines for Americans, 2010. Available at: http://www.cnpp.usda.gov/DGAs2010-PolicyDocument.htm. Accessed 8/23/2013.

Volpp, K. G., John, L. K., Troxel, A. B., Norton, L., Fassbender, J., \& Loewenstein, G. (2008). Financial incentive-based approaches for weight loss: A randomized trial. Journal of the American Medical Association, 300(22), 2631-2637.

Wadden, T. A., Butryn, M. L., \& Wilson, C. (2007). Lifestyle modification for the management of obesity. Gastroenterology, 132(6), 2226-2238.

Wadden, T. A., Crerand, C. E., \& Brock, J. (2005). Behavioral treatment of obesity. Psychiatric Clinics of North America, 28(1), 151-170, ix.

Wadden, T. A., West, D. S., Delahanty, L., Jakicic, J., Rejeski, J., Williamson, D., et al. (2006). The Look AHEAD study: A description of the lifestyle intervention and the evidence supporting it. Obesity (Silver Spring), 14(5), 737-752.

Author Information

* David O. Garcia, PhD

Canyon Ranch Center for Prevention and Health Promotion

Mel \& Enid Zuckerman College of Public Health

Division of Health Promotion Sciences

University of Arizona

1295 N. Martin Ave.

PO Box 245209

Tucson, AZ 85724-5209

Tel: (520) 626-4641

Fax: (520) 626-6600

Email: davidogarcia@email.arizona.edu

First co-author:

John M. Jakicic, PhD

Professor, Department of Health and Physical Activity 
Director, Physical Activity and Weight Management

Research Center

University of Pittsburgh

Oak Hill Commons

32 Oak Hill Court

Pittsburgh, PA 15261

Telephone: 412-383-4001

FAX: 412-383-4045

Email: jjakicic@pitt.edu

Second co-author:

Kelliann K. Davis, PhD

Research Assistant Professor, Department of Health and Physical Activity

Physical Activity and Weight Management Research Center University of Pittsburgh

Oak Hill Commons

32 Oak Hill Court

Pittsburgh, PA 15261

Telephone: 412-383-4003

FAX: 412-383-4045

Email: kkd2@pitt.edu

Third co-author:

Bethany Barone Gibbs, PhD

Assistant Professor, Department of Health and Physical

Activity

Physical Activity and Weight Management Research Center University of Pittsburgh

Oak Hill Commons

32 Oak Hill Court

Pittsburgh, PA 15261

Telephone: 412-383-4002

FAX: 412-383-4045

Email: bbarone@pitt.edu

Fourth co-author:

Lora E. Burke, PhD, MPH, FAHA, FAAN

Professor of Nursing and Epidemiology

Department of Health and Community Systems

School of Nursing University of Pittsburgh

415 Victoria Building

3500 Victoria St.

Pittsburgh, PA 15261

Telephone: 412-624-2305

Fax: 412-383-7293

Email: lbu100@pitt.edu

Fifth co-author: 
Garcia, D.O., Jakicic, J.M., Davis, K.K, Gibbs, B.B., Burke, L.E., Rickman, A.D. / Californian Journal of Health Promotion 2014, Volume 12, Issue 3, 56-70.

Amy D. Rickman, PhD, RD, LDN

Assistant Professor, Department of Health and Physical Activity

Assistant Director, Physical Activity and Weight

Management Research Center

University of Pittsburgh

Oak Hill Commons

32 Oak Hill Court

Pittsburgh, PA 15261

Telephone: 412-383-4004

Fax: 412-383-4045

Email: arickman@pitt.edu

* corresponding author 